\title{
In Vitro Dissolution Profiles of Two Diltiazem Tablet Formulations and a Compounded Capsule Formulation: A Comparative Study
}

\author{
Mateus Araújo Castro e Souza ${ }^{1,}{ }^{,}$, Carlos Eduardo de Oliveira Pereira ${ }^{1}$, \\ Fernando Henrique Andrade Nogueira², and Gerson Antônio Pianetti ${ }^{1}$ \\ ${ }^{1}$ Departamento de Produtos Farmacêuticos, Faculdade de Farmácia, Universidade Federal de Minas Gerais, Av. Pres. Antônio Carlos 6627, 31270-901, Belo \\ Horizonte, MG, Brazil \\ ${ }^{2}$ Departamento de Farmácia, Centro de Ciências da Saúde, Universidade Federal do Rio Grande do Norte, Rua General Gustavo Cordeiro de Faria, S/N, \\ 59012-570, Natal, RN, Brazil
}

\begin{abstract}
The dissolution test is usually employed to evaluate the performance of drug products. In this study, we compared the in vitro dissolution profiles of two diltiazem hydrochloride tablet formulations with that of a diltiazem hydrochloride compounded capsule formulation. Other characteristics investigated were average weight, drug content, disintegration, and uniformity of dosage units according to the USP monograph. The paddle apparatus was set at $75 \mathrm{rpm}$ in $900 \mathrm{~mL}$ of water at $37.0 \pm 0.1^{\circ} \mathrm{C}$. Samples of $10 \mathrm{~mL}$ were withdrawn at 15, 30, 60, 120, 180, and $210 \mathrm{~min}$ without replacement and immediately filtered with $0.45-\mu \mathrm{m}$ PVDF syringe filters. The samples were then analyzed employing a spectrophotometer at $237 \mathrm{~nm}$. The similarity $\left(f_{2}\right)$ and difference $\left(f_{1}\right)$ factors were calculated for dissolution profile comparison. The drug contents of the reference, generic, and compounded products were $100.01 \%, 93.17 \%$, and $98.48 \%$, respectively. All of the products showed suitable acceptance values for drug content uniformity $(3.16,8.37$, and 4.76 for reference drug, generic drug, and compounded capsule, respectively). The generic drug formulation showed a calculated $f_{2}$ value between 50 and 100 and an $f_{1}$ value less than 15 . It was not possible to calculate the $f_{1}$ and $f_{2}$ values for the compounded capsules because they showed a drug release greater than $85 \%$ in $15 \mathrm{~min}$. The generic and reference drugs were similar in relation to all tests. Furthermore, the generic and reference drug dissolution profiles were similar. The compounded capsules, which readily released the active ingredient, were not adequate only in the dissolution test. Further studies are necessary to investigate if the quick release of diltiazem from the drug products may pose any risks for patients, especially in Brazil where the compounded capsules are prescribed interchangeably with the reference drug.
\end{abstract}

KEYWORDS: Diltiazem hydrochloride; compounded capsules; dissolution; in vitro dissolution profile.

\section{INTRODUCTION}

To obtain registration for generic and similar drugs in Brazil, among other requirements, the manufacturer must submit its products to pharmaceutical equivalence and bioequivalence studies $(1,2)$.

Pharmaceutical equivalence studies are conducted to prove that two drug products contain the same drug; that is, the salt or ester of the therapeutically active molecule, the dosage form, route of administration, and the concentration or potency are identical. The dissolution test and the comparative study of in vitro dissolution profiles are used to determine the performance of the dosage form (3).

The in vitro dissolution of immediate-release dosage forms is an important tool to ensure batch to batch quality. Because the dissolution of the dosage form has an important role in drug bioavailability, in vitro dissolution may be utilized to predict the in vivo behavior of a drug product once in vitro-in vivo correlation has been established (4).

Moreover, Brazilian law does not require dissolution testing and a comparative study of in vitro dissolution profiles for compounded drug products. The Brazilian law recommends carrying out dissolution profile studies only for narrow therapeutic index drug products (5).

Diltiazem hydrochloride, chemically 1,5-benzothiazepin4(5H)-one,3-(acetyloxy)-5-[2-(dimethylamino)ethyl]2,3-dihydro-2-(4-methoxyphenyl)-, monohydrochloride (Figure 1), is a drug widely used in clinical practice. The pharmaceutical dosage forms can be purchased in drug stores (tablets) or compounded in pharmacies (capsules).

*Correspondence author 
Diltiazem hydrochloride capsules are compounded in the same dosage strengths as those of tablets available on the Brazilian market and are used as a therapeutic alternative to the reference drug product, an approach that is forbidden in the United States (6). Nevertheless, studies comparing the dissolution profiles of compounded capsules and tablets have been reported $(7,8)$.

The aim of this study was to compare the in vitro dissolution profiles of diltiazem hydrochloride tablets and compounded capsules employing the USP dissolution method for tablets.

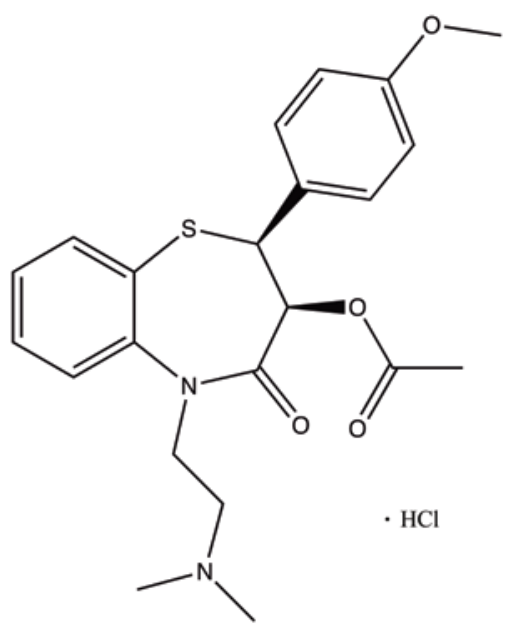

Figure 1. Chemical structure of diltiazem hydrochloride.

\section{MATERIALS AND METHODS}

\section{Chemical, Reagents, and Materials}

Diltiazem hydrochloride reference standard (100.2\% purity) was obtained from the Brazilian Pharmacopoeia (Brasília, DF, Brazil). Ultrapure water for the dissolution tests was obtained from a Gehaka OS1OLXE reverse osmosis system (São Paulo, SP, Brazil). Ultrapure water for the chromatographic analysis was obtained from a Millipore system (Bedford, MA, USA). Methanol (HPLC grade) was purchased from J. T. Baker (Phillipsburg, NJ, USA). Trifluoroacetic acid (HPLC grade) was purchased from Tedia (Fairfield, OH, USA).

\section{Instrumentation}

HPLC analyses were carried out on a Thermo Finnigan Surveyor System (San Jose, CA, USA) composed of a quaternary pump, degasser, autosampler, column oven, and a photodiode array detector. The chromatographic separation was performed on a Merck Millipore Purospher Star C18 column ( $150 \times 4.6 \mathrm{~mm}$ i.d.; 5 - $\mu \mathrm{m}$ particle size), maintained at $30{ }^{\circ} \mathrm{C}$. UV detection was performed at
$240 \mathrm{~nm}$. The injection volume was $20 \mu \mathrm{L}$. The mobile phase was a mixture of $0.05 \%(\mathrm{v} / \mathrm{v})$ trifluoroacetic acid aqueous solution and $0.05 \%(\mathrm{v} / \mathrm{v})$ trifluoroacetic acid methanolic solution $(44: 56, \mathrm{v} / \mathrm{v})$ at a flow rate of $1.0 \mathrm{~mL} /$ $\mathrm{min}$. The disintegration analyses were carried out on a Nova Ética system (Vargem Grande Paulista, SP, Brazil). The dissolution analysis were carried out on an Agilent Technologies Varian VK7025 dissolution system (Santa Clara, CA, USA). The UV analyses were carried out on a Shimadzu spectrophotometer UV 1800 (Kyoto, Honshu, Japan).

\section{Comparative Analysis of Tablets and Capsule Formulations}

The two diltiazem hydrochloride tablets were purchased from a drug distributor at Belo Horizonte, MG, Brazil. Twenty tablets of each formulation were weighed individually, and the weight variation was calculated. The contents of twenty capsules were weighed individually, and the weight variation was calculated employing the method from the Brazilian Pharmacopoeia (9). The drug content was determined using the HPLC method previously developed and validated by our group (10). For the tablets, a sample was taken from twenty crushed tablets of each formulation, and for the capsules, a sample was taken from the contents of twenty capsules. The mean peak area and concentration were obtained and used to calculate the percentage of diltiazem in each product. The assays were performed in triplicate. The content uniformity was calculated according to the Brazilian Pharmacopoeia (9) and USP (11). The disintegration was also verified for all the formulations employing the Brazilian Pharmacopoeia and USP methods.

\section{Dissolution}

The analyses were performed employing the USP method (11). The dissolution parameters were water as dissolution medium with Apparatus 2 (paddle) at $75 \mathrm{rpm}$. Each tablet or capsule was placed in one of the six vessels, each containing $900 \mathrm{~mL}$ of purified water. The capsules were first placed inside sinkers to prevent floating. The samples were analyzed at $237 \mathrm{~nm}$, and fresh medium was used as the blank. A calibration curve was used for drug quantification. Samples of $10 \mathrm{~mL}$ were withdrawn at $15,30,60,120,180$, and 210 min without medium replacement and immediately filtered with $0.45-\mu \mathrm{m}$ PVDF syringe filters. Tablet samples withdrawn at 15 and 30 min did not require dilution. Tablet samples withdrawn at $60,120,180$, and $210 \mathrm{~min}$ and capsule samples required dilution: $4 \mathrm{~mL}$ of the dissolution sample was pipetted and diluted to $25 \mathrm{~mL}$ with water. At the end of the dissolution test, six samples of each product were also 
injected into the chromatograph employing the analytical method previously described to verify drug stability in the dissolution conditions. The presence or absence of degradation peaks in the chromatograms was evaluated.

\section{Preparation of Standard Solutions}

Approximately $10 \mathrm{mg}$ of diltiazem hydrochloride was accurately weighed and transferred to a $100-\mathrm{mL}$ volumetric flask, followed by the addition of $50 \mathrm{~mL}$ of water. The flask was sonicated for $10 \mathrm{~min}$ and filled to the mark with water. Aliquots of the stock standard solution were diluted to obtain standard solutions at the following concentrations: 2.0, 4.0, 6.0, 8.0, 10.0, and 12.0 $\mu \mathrm{g} / \mathrm{mL}$. The standard solutions were used to construct a calibration curve and thus to determine drug release in the dissolution tests.

\section{Statistical Analyses}

Microsoft Office Excel 2007 was used to calculate the similarity $\left(f_{2}\right)$ and difference $\left(f_{1}\right)$ factors. The similarity factor was calculated only if either the reference or test products released less than $85 \%$ of the active ingredient within 15 min with $n=12$ (12).

\section{RESULTS}

The reference drug had an average weight of $186.77 \pm$ $1.80 \mathrm{mg}$, the generic drug had an average weight of 145.78 $\pm 1.77 \mathrm{mg}$, and the compounded capsule had an average content weight of $176.06 \pm 4.09 \mathrm{mg}$. The drug contents of reference, generic, and compounded products were $100.01 \%, 93.17 \%$, and $98.48 \%$, respectively. All of the products showed suitable acceptance values (AV) for drug content uniformity $(3.16,8.37$, and 4.76 for reference drug, generic drug, and compounded capsule, respectively). The reference and generic products did not disintegrate in $30 \mathrm{~min}$, whereas the compounded capsule disintegrated in $5 \mathrm{~min}$.

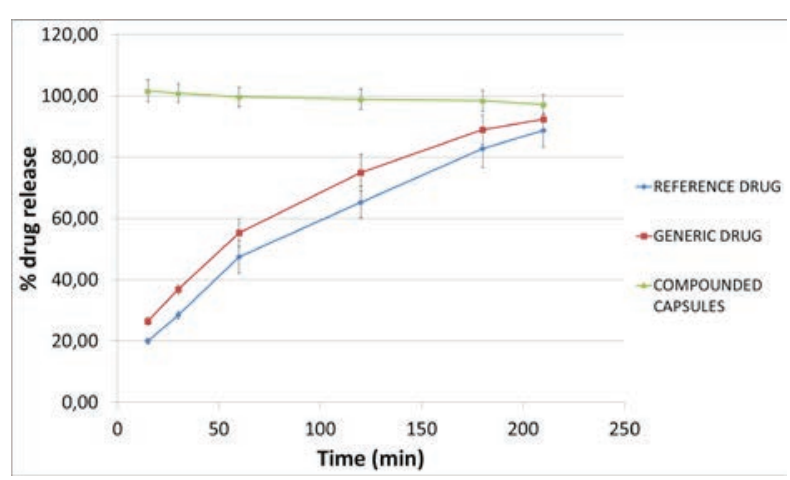

Figure 2. Dissolution profiles of reference and generic drugs and compounded capsules.
The reference and generic products released more than $80 \%$ of diltiazem in $3 \mathrm{~h}$, whereas the compounded capsule released more than $80 \%$ of diltiazem in only $15 \mathrm{~min}$ (Figure 2). The $f_{2}$ value of 56.60 and $f_{1}$ value of 12.73 were obtained for the generic product when compared with the reference product. It was not possible to calculate $f_{2}$ and $f_{1}$ values for the compounded product, because the compounded capsule released more than $85 \%$ of the active ingredient in $15 \mathrm{~min}$.

\section{DISCUSSION}

The results for average weight determination, assay, uniformity of dosage units, and dissolution were acceptable for the reference and generic drugs. The results for compounded capsules, however, were satisfactory only for content average weight, assay, and uniformity of dosage units.

Tablets are usually obtained by the compression of a mixture of active ingredient and excipients that have different functions and may be formulated to provide immediate or modified release depending on the excipients and the manufacturing processes employed. Hard gelatin capsules disintegrate in contact with water, promptly releasing their contents in the stomach. To improve the release and distribution of capsule contents, disintegrants can be added. Capsules may be produced to show modified release using coated pellets containing the drug (13). Because the compounded capsules analyzed were not formulated with the pellet system, they did not exhibit modified release but readily released their contents into the dissolution medium. The reference and generic drug tablets, on the other hand, were formulated with hydrogenated castor oil, an excipient that provides a delayed drug release in concentrations of $5.0-20.0 \%$ (14). However, it is important to discuss whether the observed differences between the dissolution profiles of the compounded capsules and those of the reference drug have any clinical impact.

Studies comparing compounded capsules and tablets of propranolol and prednisone have been reported (7, 8). These studies compared the dissolution profiles of the compounded capsules with those of the respective reference drug tablets. The results show significant differences between them for both drugs and are agree with those obtained in this study.

The diltiazem hydrochloride tablets showed in vitro modified release as evidenced by the dissolution profiles. The dissolution test used in this study has two sampling times, one at $30 \mathrm{~min}$ and the other at $3 \mathrm{~h}$. The $30-\mathrm{min}$ 
sampling time ensures that diltiazem release from the dosage form is not fast, to comply with the acceptance criterion of a release less than $60 \%$ of labeled amount (11). The diltiazem hydrochloride tablets available in the market provide a slow in vivo release, with time-to-peak concentration ( $\left.T_{\max }\right)$ between 3 and $4 \mathrm{~h}$ (15).

A study conducted by Pool and colleagues (16) demonstrated that immediate-release tablets have equivalent effectiveness to modified-release capsules for the treatment of angina pectoris, with no difference in efficacy or incidence of adverse reactions. Furthermore, a study (17) of diltiazem as monotherapy for the treatment of hypertension demonstrated that diltiazem immediaterelease tablets have good efficacy when taken three to four times a day.

However, some studies (18-20) have demonstrated the potential risks of calcium antagonists formulated in immediate-release dosage forms for the treatment of hypertension in patients with coronary heart disease. Immediate-release pharmaceutical dosage forms of nifedipine caused ischemic events and an increase in coronary mortality when used at high doses. There are some inconsistent reports regarding adverse reactions related to the immediate-release formulations of nifedipine, diltiazem hydrochloride, and verapamil hydrochloride. Therefore, it is preferable to treat hypertension with long lasting calcium channel blockers or prolonged-release formulations.

Randomized clinical trials (21) conducted to compare the effects of drugs containing diltiazem, diuretics, betablockers or diuretics, and beta-blocker associations followed 10,881 patients from October 1992 to October 1999. The results show that diltiazem is as effective as diuretics, beta-blockers, or a combination of both in the prevention of stroke, acute myocardial infarction, and other cardiovascular events. However, the authors reported that diltiazem immediate-release dosage forms were initially administered, and after 1997 they were replaced by an extended-release formulation. The authors did not provide the explanation for this replacement.

The dissolution test for diltiazem hydrochloride tablets published in 1990 in USP XXII (22) was different from the test currently described. The dissolution medium was $900 \mathrm{~mL}$ of water at $50 \mathrm{rpm}$ and a time of $45 \mathrm{~min}$. The acceptance criterion was not less than $75 \%(Q)$ of the labeled amount of diltiazem hydrochloride tablet released in $45 \mathrm{~min}$. According to the parameters set for the dissolution test, it can be inferred that the diltiazem hydrochloride tablets available at the time were of immediate release.
However, the dissolution test for diltiazem hydrochloride tablets published in 1995 in USP 23 (23) showed a change, becoming similar to the test currently employed. It used $900 \mathrm{~mL}$ of water as the dissolution medium, paddles at $100 \mathrm{rpm}$, and two sampling times, $30 \mathrm{~min}$ and $3 \mathrm{~h}$. The acceptance criterion was no more than $60 \%$ of the labeled amount dissolved in $30 \mathrm{~min}$ and at least $80 \%$ of the labeled amount dissolved in $3 \mathrm{~h}$. Although it is unclear, it can be assumed that the dissolution test was modified because the formulation was altered to target a modified drug release, possibly due to the reports of increased risk of cardiovascular events in patients using immediaterelease tablets of calcium antagonists.

\section{CONCLUSION}

Results for generic and reference drugs were acceptable for all tests. Furthermore, the generic and reference drug dissolution profiles were similar. Test results for the compounded capsules were not acceptable only for the dissolution test. The dissolution profile of the compounded capsule was different from that of the reference drug, wherein the capsules readily released the active ingredient while tablets presented a prolonged-release mechanism. Therefore, it is necessary to investigate if the use of diltiazem immediate-release dosage forms may cause adverse cardiovascular effects. Moreover, prescribers should be aware of the pharmacokinetic differences and possible risks related to the use of diltiazem compounded capsules, especially in Brazil, where the compounded capsules are prescribed interchangeably with the reference drug.

\section{ACKNOWLEDGMENTS}

The authors would like to thank CAPES and the Brazilian Pharmacopeia for the financial support.

\section{CONFLICT OF INTEREST}

The authors declare that there are no conflicts of interest regarding this manuscript.

\section{REFERENCES}

1. Law No. 9,787, of February 10, 1999-Alters Law No. 6360 of September 23, 1976, which provides for health surveillance, establishes the generic medicine, provides for the use of generic names in pharmaceutical products, and provides other measures. Presidency of the Republic of Brazil: Brasília, 1999. http://pesquisa.in.gov.br/imprensa/jsp/visualiza/index.jsp?jor nal=1\&pagina=57\&data=11/02/1999 (accessed Mar 20, 2017).

2. RDC Resolution No .133/2003, of May 29, 2003-Provides for registration of similar medications and provides other measures. Brazilian Health Surveillance Agency (ANVISA): Brasília, 2003. http://pesquisa.in.gov.br/imprensa/jsp/visualiza/index.jsp?jor 
nal=1\&pagina=25\&data=02/06/2003 (accessed Mar 20, 2017).

3. Biofarmacotécnica, 1st ed.; Storpirtis, S., Gonçalves, J. E., Chiann, C., Gai, M. N., Eds.; Guanabara Koogan: Rio de Janeiro, 2011.

4. Marroum, P. J. History and Evolution of the Dissolution Test. Dissolution Technol. 2014, 21 (3), 11-16. DOI: 10.14227/ DT210314P11.

5. Good Handling Practices of Compounded and Officinal Preparations for Human Use in Compounding Pharmacies-RDC n.67/2007. Brazilian Health Surveillance Agency (ANVISA): city?, 2007. http://pesquisa.in.gov.br/imprensa/jsp/visualiza/index. jsp?jornal=1\&pagina=29\&data=09/10/2007 (accessed Mar 20, 2017).

6. Drug Quality and Security Act. Public Law 113-54; Code of Federal Regulations, 127 Stat. 587, 2013. https://www.congress. gov/113/plaws/publ54/PLAW-113publ54.pdf (accessed Aug 31, 2016).

7. Barancelli, R.; Ferreira, J. R. N. Avaliação físico-química de cápsulas manipuladas de prednisona no município de Erechim, RS. Evidência 2007, 7 (1), 51-62. http://editora.unoesc.edu.br/ index.php/evidencia/article/view/1860/932 (accessed Mar 20, 2017).

8. Júnior, F. P.; Escarrone, A. L. V. E.; Bittencourt, C. F.; Santos, M. R.; Laporta, L. V. Perfis de dissolução comparativos entre cápsulas manipuladas de cloridrato de propranolol e o medicamento referência. Disciplinarum Scientia 2005, 6 (1), 35-43. http:// sites.unifra.br/Portals/36/CSAUDE/2005/perfil-F.pdf (accessed Sep 9, 2016).

9. Brazilian Pharmacopeia, 5th ed.; Brazilian Health Surveillance Agency: Brasília, 2010.

10. Souza, M. A. C.; Pianetti, G. A.; Nogueira, F. H. A. Development of an analytical method for determination of diltiazem in solid dosage forms.. Proceedings of the Brazilian Symposium on Chromatography and Related Techniques, Campos do Jordão, SP, Brazil, September 4-6, 2014.

11. The United States Pharmacopeia and National Formulary USP 36-NF 31; The United States Pharmacopeial Convention, Inc.: Rockville, MD, 2013.

12. Stuart, A. V.; Clement, Y.; Sealy, P.; Löbenberg, R.; MontaneJalme, L.; Maharaj, R. G.; Maxwell, A. Comparing the Dissolution Profiles of Seven Metformin Formulations in Simulated Intestinal Fluid. Dissolution Technol. 2015, 22 (1), 17-21. DOI: 10.14227/

\section{DT220115P17.}

13. Allen, L. V., Jr.; Popovich, N. G.; Ansel, H. C. Ansel's Pharmaceutical Dosage Forms and Drug Delivery Systems; Lippincott Williams \& Wilkins: Baltimore, MD, 2007.

14. Handbook of Pharmaceutical Excipients, 6th ed.; Rowe, R. C., Sheskey, P. J., Quinn, M. E., Eds.; Pharmaceutical Press: London, 2009.

15. Sweetman, S. C., Ed. Martindale, the Complete Drug Reference, 36th ed.; Pharmaceutical Press: London, 2009; p 1265.

16. Pool, P. E.; Thadani, U.; Miller, A. B.; Fromell, G. J.; Eff, J. Conversion from immediate-release to extended-release diltiazem in angina pectoris. Clin. Cardiol. 1994, 17 (9), 484-488. DOI: 10.1002/ clc.4960170905.

17. Pool, P. E.; Nappi, J. M.; Weber, M. A. Antihypertensive monotherapy with tablet (Prompt-release) diltiazem: Multicenter controlled trials. Cardiovasc. Drugs Ther. 1990, 4 (4), 1089-1096. DOI: 10.1007/BF01856504.

18. AHFS Drug Information; McEvoy, G. K., Ed.; American Society of Healthy-System Pharmacists: Bethesda, MD, 2004.

19. The Sixth Report of the Joint National Committee on Prevention, Detection, Evaluation, and Treatment of High Blood Pressure. Arch. Intern. Med. 1997, 157 (21), 2413-2446. DOI: 10.1001/ archinte.1997.00440420033005.

20. Sociedade Brasileira de Cardiologia; Sociedade Brasileira de Hipertensão; Sociedade Brasileira de Nefrologia. VI Brazilian Hypertension Guidelines. Arq. Bras. Cardiol. 2010, 95 (1, Suppl. 1), 1-51. DOI: 10.1590/S0066-782X2010001700001.

21. Hansson, L.; Hedner, T.; Lund-Johansen, P.; Kjeldsen, S. E.; Lindholm, L. H.; Syvertsen, J. O; Lanke, J.; de Faire, U.; Dahlöf, B.; Karlberg, B. E. Randomised trial of effects of calcium antagonists compared with diuretics and $\beta$-blockers on cardiovascular morbidity and mortality in hypertension: the Nordic Diltiazem (NORDIL) study. Lancet 2000, 356 (9227), 359-365. DOI: 10.1016/S0140-6736(00)02526-5.

22. The United States Pharmacopeia and National Formulary USP XXII-NF XVII; The United States Pharmacopeial Convention, Inc.: Rockville, MD, 1990.

23. The United States Pharmacopeia and National Formulary USP 23-NF 18; The United States Pharmacopeial Convention, Inc.: Rockville, MD, 1995. 